\title{
STAT3-Ser/Hes3 Signaling: A New Molecular Component of the Neuroendocrine System?
}

\author{
Authors \\ P. Nikolakopoulou' ${ }^{1}$, S. W. Poser ${ }^{1}$, J. Masjkur ${ }^{1}$, M. Fernandez Rubin de Celis ${ }^{1}$, L. Toutouna', C. L. Andoniadou ${ }^{2}$, \\ R. D. McKay ${ }^{3}$, G. Chrousos ${ }^{4}$, M. Ehrhart-Bornstein ${ }^{1}$, S. R. Bornstein ${ }^{1}$, A. Androutsellis-Theotokis ${ }^{1,5,6}$ \\ Affiliations \\ Affiliation addresses are listed at the end of the article
}

Key words
STAT3
Hes3
stem cells

received 03.11 .2015

accepted 16.12.2015

\section{Bibliography \\ DOI http://dx.doi.org/ \\ 10.1055/s-0041-111699 \\ Published online: \\ January 19, 2016 \\ Horm Metab Res 2016; \\ 48: 77-82 \\ (c) Georg Thieme Verlag KG Stuttgart · New York \\ ISSN 0018-5043}

\section{Correspondence}

\section{A. Androutsellis-Theotokis}

Department of Medicine University of Dresden Fetscherstrasse 74 01307 Dresden

Germany

Tel.: + 49/796/5 690

Fax: + 49/351/458 6398

andreas.theotokis@uniklinikumdresden.de

\section{Abstract \\ $\nabla$}

The endocrine system involves communication among different tissues in distinct organs, including the pancreas and components of the Hypothalamic-Pituitary-Adrenal Axis. The molecular mechanisms underlying these complex interactions are a subject of intense study as they may hold clues for the progression and treatment of a variety of metabolic and degenerative diseases. A plethora of signaling pathways, activated by hormones and other endocrine factors have been implicated in this communication. Recent advances in the stem cell field introduce a new level of complexity: adult progenitor cells appear to utilize distinct signaling pathways than the more mature cells in the tissue they co-reside. It is therefore important to elucidate the signal transduction requirements of adult progenitor cells in addition to those of mature cells. Recent

\section{Introduction}

(

The existence of neural stem cells (NSCs) in the adult mammalian brain was inferred in 1962 by Joseph Altman who demonstrated the incorporation of tritiated thymidine in adult neurons [1]. Later, Kaplan, Gould, and colleagues provided supporting evidence [2-6]. Goldman and Nottebohm reported similar phenomena in the adult songbird brain, demonstrating massive seasonal neuronal turnover as male birds develop new songs [7]. Hockfield and McKay identified nestin as a biomarker of fetal NSCs [8], while Cattaneo and McKay developed cell culture techniques that allowed the maintenance of these cells in vitro [9]. Subsequently, Reynolds and Weiss were able to isolate and culture NSCs from the adult mammalian brain, which exhibited proliferation capability, as well as the potential of differentiation into neurons and glia after treatment with evidence suggests that a common non-canonical signaling pathway regulates adult progenitors in several different tissues, rendering it as a potentially valuable starting point to explore their biology. The STAT3-Ser/Hes3 Signaling Axis was first identified as a major regulator of neural stem cells and, subsequently, cancer stem cells. In the endocrine/neuroendocrine system, this pathway operates on several levels, regulating other types of plastic cells: (a) it regulates pancreatic islet cell function and insulin release; (b) insulin in turn activates the pathway in broadly distributed neural progenitors and possibly also hypothalamic tanycytes, cells with important roles in the control of the adrenal gland; (c) adrenal progenitors themselves operate this pathway. The STAT3-Ser/Hes3 Signaling Axis therefore deserves additional research in the context of endocrinology.

appropriate growth factors in vitro [10]. These and other studies led to efforts aimed at promoting brain repair by either transplanting newly formed neurons into the brain, therefore replacing lost cells, or by stimulating endogenous NSCs (eNSCs) to facilitate their neuroprotective role following brain injury or against degenerative disease [11,12].

Cell replacement strategies have recently received an enormous boost by reprogramming technologies that allow patient-specific cell sources to be converted into immature cells (somatic cells into embryonic stem cell-like cells), which can then be directed to differentiate towards specific cell fates and then be grafted into the patient [13]. However, the immense cytoarchitectural complexity of the brain hinders their successful implementation. Graft-derived neurons need to be precisely placed and they oftentimes should connect brain areas that are 
centimeters away from each other. In parallel to these efforts, scientists have been exploring the possibility to pharmacologically target eNSCs to increase their number and putative neuroprotective functions. These cells are already naturally incorporated into the tissue, within specific microenvironments (the neurovascular niche) and by understanding the signals that these cells respond to, it is possible to increase their number several fold through direct local injection of a number of soluble factors. Such treatments have proven highly consequential, leading to long-term behavioral improvement in models of ischemic stroke and Parkinson's disease [14-18].

To take full advantage of eNSCs, many aspects of their biology need to be further understood, including the molecular mechanisms that regulate their number and fate specification, to allow the direction of their fate to appropriate cell types for replacement, neuroprotection, or immunomodulation. Here we focus on a recently identified signaling pathway that regulates the number of NSCs in vitro and in vivo [19]. A major input into the pathway is insulin, providing a new molecular mechanism via which the pancreas may regulate aspects of brain function. New evidence points towards the operation of this pathway in the hypothalamus and adrenal gland [20], suggesting that it has a broad role in the neuroendocrine system, deserving further study.

\section{The STAT3-Ser/Hes3 Signaling Axis in NSCs} $\nabla$

NSCs apparently interpret signaling pathways in their own distinct ways. For example, whereas many cell types in the body utilize the JAK/STAT pathway for growth and survival, this leads to the differentiation of NSCs [21-24]. Specifically, tyrosine phosphorylation of STAT3 is a key component of the survival pathway of most cell types, but NSCs avoid this phosphorylation in order to prevent differentiation into glia. Instead, NSCs utilize the serine phosphorylation of STAT3 for their survival, which is largely redundant for many other cell types [16]. Several inputs into STAT3-serine phosphorylation have been identified, including a noncanonical branch of Notch signaling (activated by Notch receptor ligands such as Delta4 and Jagged1), angiopoietin 2 (a ligand of the Tie2 receptor), basic fibroblast growth factor (bFGF), and insulin [16-18,25,26]. These treatments lead to the transcriptional induction of Hes3, a transcription factor/passive repressor belonging to the Hes/Hey family of basic helix-loophelix genes $[27,28]$. This pathway is opposed by JAK and p38 MAP kinases and, therefore, inhibitors of these kinases promote its activation and NSC survival. Hes3 itself mediates many of these functions, as adult cultured NSCs show a reduced response to Delta4 and insulin stimulation, and to JAK inhibition [17]. Hes3 RNA interference also opposes the growth of cultured cancer stem cells from human glioblastoma multiforme biopsies [29].

Pharmacological activation of this pathway has powerful consequences as it directly promotes the survival of cultured NSCs from many sources. In vivo, the same treatments increase the number of putative eNSCs and induce long-lasting neuroprotection in models of ischemic stroke and Parkinson's disease [16]. One of these treatments is the direct injection of insulin into the lateral ventricle of adult rats, suggesting that circulating insulin may also regulate eNSC number and function, and rendering the endocrine pancreas a key regulator of the eNSC population in both established neurogenic zones, such as the subventricular zone (SVZ) and the subgranular zone (SGZ) of the dentate gyrus of the hippocampus, but also in the brain parenchyma [17]. The disease-modifying functions of this pathway may involve, in part, cell replacement but more likely, the increased release of neuroprotective factors [30]. Hes3, in particular, may also be involved in the reprogramming of induced pluripotency cells and adult somatic cells to the NSC fate, suggesting not only roles in promoting NSC growth but also specification [31,32].

\section{STAT3-Ser/Hes3 Signaling Axis in the Pancreatic Islet $\nabla$}

It appears likely, then, that the endocrine pancreas can regulate aspects of brain functions, such as neuroprotection and regeneration, via the release of insulin and its actions on endogenous NSCs. Molecular mechanisms that regulate insulin production/ release and pancreatic islet beta cell properties may thus be directly relevant to brain function [33]. Remarkably, the same signaling pathway also regulates key functions of pancreatic islets, as well as their resistance to damage. These observations suggest that the STAT3-Ser/Hes3 Signaling Axis in the pancreas regulates the same signaling pathway in eNSCs and with it, the function of both of these cell types.

Specifically, Hes3 is expressed in pancreatic islets and Hes3 null mice exhibit more pronounced damage to the pancreatic islet beta cell population when treated with the toxin streptozotocin (STZ), relative to wild type controls [34], resulting in a greater loss of beta cells and an earlier diabetic phenotype, as assessed by blood glucose levels. Following STZ-induced damage, Hes3 promoter activity (in this study the activity of only one of the 2 promoters, Hes3a, was assessed) is elevated, suggesting an involvement in pancreatic islet regeneration. In fact, Hes3 null mice exhibit reduced islet regeneration following partial STZinduced damage [Masjkur et al., in press]. In the exocrine pancreas, Hes3 null mice fail to upregulate neurogenin3, an indicator of regenerative responses in these STZ models [35].

Mouse insulinoma cell lines cultured under defined conditions also express Hes3 and Hes3 RNA interference regulates gene expression, reduces cell growth, and opposes glucose-stimulated insulin release. In the absence of an insult to pancreatic islet cells (STZ), no phenotype has yet been reported [36]. For example, homozygous null mice for Hes3 are healthy, breed well, have normal blood glucose levels and glucose tolerance test (GTT) scores, and normal gross pancreatic islet morphology, suggesting that this pathway has relevance in conditions of damage and regeneration. These observations also showcase that the lack of obvious phenotypes in genetic models does not preclude the manifestation of deficiencies in paradigms of damage, stress, or other insults. These signaling concepts may be of relevance to diabetes-mediated encephalopathy which, at the early stages exhibits damage in the neurovascular niche in the brain through oxidative and vascular damage and at later stages exhibits impaired neurogenic potential [37].

\section{STAT3-Ser/Hes3 Signaling Axis in the Adrenal Cortex and Medulla \\ $\nabla$}

We recently reported Hes3 expression in the bovine adrenal medulla and in cultures of chromaffin progenitor cells from this tissue [38]. Using a reporter mouse strain where the Hes3 gene has been replaced by the lac $Z$ gene under the control of the 
Hes3a promoter (one of the 2 known promoters of Hes3) [39], we also showed the expression of Hes 3 in the mouse medulla, corroborating the bovine data ( $\bullet$ Fig. 1 ). In addition, we reported Hes3a promoter activity in the adrenal cortex. In the cortex, Hes3 expression was most prominent in the zona glomerulosa, where sonic hedgehog (Shh)-expressing progenitor cells reside [40]. Because in NSCs, Hes3 is a positive regulator of Shh expression [16], this observation raises the question of whether Hes3 is expressed in adrenocortical progenitors and whether it functions to induce Shh expression. Copper chelation by a cuprizonerich diet induces massive upregulation of Hes3a promoter activity further suggesting that different insult paradigms should be investigated to unveil roles of the STAT3-Ser/Hes3 Signaling Axis ( $\bullet$ Fig. 1).

\section{STAT3-Ser/Hes3 Signaling Axis in Tanycytes of the Hypothalamus? \\ $\nabla$}

The STAT3-Ser/Hes3 Signaling Axis regulates pancreatic beta cells as well as neural and neuroendocrine stem cells and progenitor cells in the adult brain and adrenal gland. Given this broad range of cells that utilize the pathway, it is reasonable to speculate that hypothalamic tanycytes may also be subject to regulation by this pathway. Tanycytes are involved in the transport of chemicals from the cerebrospinal fluid to the brain and which participate in the metabolic regulation of the organism [41]. In addition, they have putative progenitor cell properties [42-44]; why a cell with such defined function may also have progenitor properties is a subject of great interest with potential ramifications to the fields of neurodegenerative disease and metabolic control.

Indeed, tanycytes of the median eminence express Hes3 as demonstrated by immunolabeling for beta-galactosidase that is expressed under the control of one of the 2 Hes 3 promoters (the one that induces the transcription of the Hes3a product) ( $\odot$ Fig. 1). It remains to be determined how this pathway may affect the stem/progenitor cell properties of tanycytes and, as a consequence, metabolic regulatory functions of the hypothalamus.

The adult hypothalamus is derived from the ventral diencephalon, which contains 2 distinct proliferative zones; the lateral and the midline zone, which form the peripheral and the core region of the hypothalamus, respectively [45-47], and it is a key regulator of many physiological functions and homeostatic mechanisms including growth, feeding/energy expenditure and reproduction. Impaired hypothalamic maturation is responsible for a variety of behavioral and somatic diseases like obesity, infertility, and mood disorders [48]. The hypothalamus consists of a variety of nuclei that form a highly complex neuronal network controlling functions. To regulate body weight, the hypothalamus must interpret and integrate incoming signals such as levels of glucose, free fatty acids and amino acids but also hormones like leptin, ghrelin, and insulin from the periphery (stomach, pancreas, and adipose tissue) [49]. It then needs to synthesize and secrete hormones that will affect other endocrine glands such as the pituitary and, subsequently, the adrenal, affecting a wide range of functions, including stress adaptation, mood/emotions, digestion, the immune system, sexual function, and energy storage/expenditure [48].

In the more traditionally established neurogenic zones of the adult brain, the SVZ and SGZ, it is becoming increasingly appreciated that immature, highly plastic cell populations are able to play important roles in brain function by providing new cells and, possibly, signals to the tissue $[50,51]$. Similar concepts appear to hold true in the hypothalamus as well. Many of the key nuclei controlling energy balance located in close proximity to the 3rd ventricle contain a population of ependymal cells. This population can be further divided into 2 subgroups: (i) the ciliated ependymal cells with very short processes lining the dorsal part of the ventricle; (ii) the tanycytes, which lack cilia but have microvilli, distinct apical specializations, as well as long processes projecting into the brain parenchyma, lining the ventral part of the ventricle $[52,53]$. The tanycytes are further divided into 4 distinct subgroups; the $\alpha 1$ and $\alpha 2$ tanycytes, which are located in the dorsal part of the ventricle and are close to the ventromedial hypothalamic nuclei and the $\beta 1$ and $\beta 2$ tanycytes, which are located more ventrally and in close proximity to the arcuate nucleus and the median eminence. $\beta 2$ tanycytes have direct access to circulating plasma due to the unique position of the median eminence outside the blood-brain barrier; with their processes in close proximity to neuronal populations controlling energy homeostasis (e.g., AgRP and POMC neurons in the arcuate nucleus), they may play a particularly important role in energy homeostasis and body weight balance $[41,52]$. The discovery of tanycytes can be traced to decades ago when Rita Levi Montalcini together with her colleague Stanley Cohen discovered a specific cell population with stem cell like characteristics that were highly responsive to nerve growth factor (NGF) [54]. A striking morphological characteristic of tanycytes is their long processes reaching several hundred microns in length making them capable of contacting the hypothalamic nuclei and the neurons within them that play key roles in the control of energy homeostasis.

The question of how the stem cell/progenitor properties of tanycytes come into play in hypothalamic function is still under intense investigation. Tanycytes may be non-terminally specified immature cells tasked with the ability for metabolic sensing (a complex biochemical function) and, at the same time, the capacity to contribute to tissue remodeling by generating new neurons. In this way, tanycytes may be able to dynamically contribute to tissue plasticity, in response to dietary and other changes $[41,52,53,55,56]$. Over the last decade, a variety of studies support this view and demonstrate that tanycytes express a number of markers in common with neural stem cells/ progenitor cells including nestin, vimenting, doublecortin (for early neurons), and Sox2 [43,44,57-63].

Central administration of ciliary neurotrophic factor (CNTF) results in weight loss and induces neurogenesis in the arcuate nucleus and the ventromedial hypothalamus, suggesting a relation between the 2 processes [64]. High fat diet-induced inflammation results in increased apoptosis and neuronal depletion in the hypothalamus [65]. The neuronal deficit may involve both increased apoptosis of existing neurons, as well as the depletion of neurogenic tanycytes, through an IKK $\beta / N F-K \beta$-mediated mechanism in $\beta 2$ tanycytes $[44,66,67]$. The median eminence (containing $\beta 2$ tanycytes) appears to be a particularly neurogenic zone that responds to high fat diet by increasing neurogenesis. Such plasticity may be of consequence to metabolic regulation as blocking neurogenesis by focused irradiation of the hypothalamus attenuated the body weight increases that are normally induced by high fat diet [43].

The lineage relation among different tanycyte subpopulations is not clear, although $\alpha$ tanycytes seem to be more robust at selfrenewing than $\beta$ tanycytes, as suggested by lineage tracing [68] 


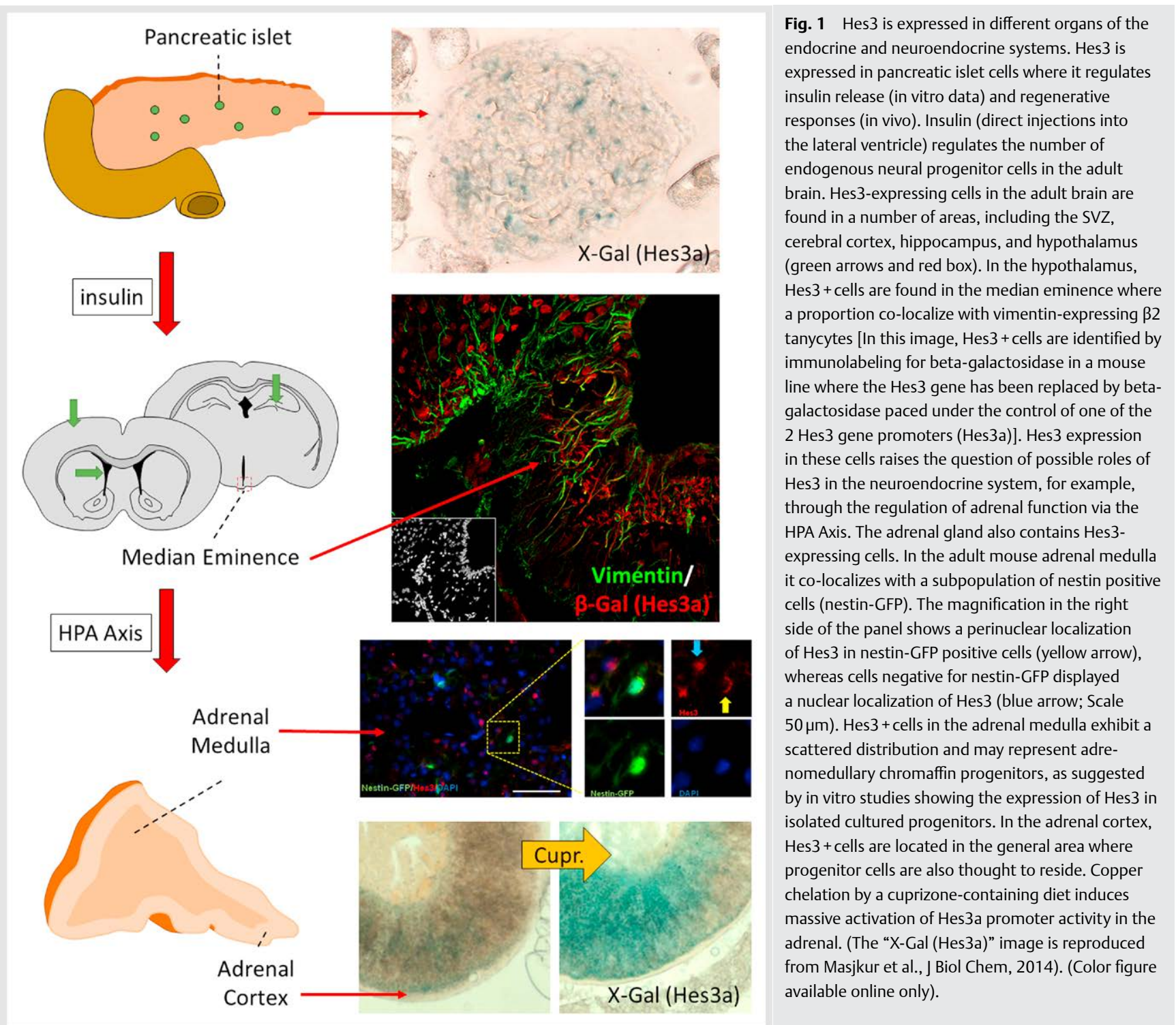

and neurosphere formation experiments [69]. Whereas there is still uncertainty as to whether $\beta 2$ tanycytes in the median eminence represent bona fide stem cells or neural progenitors with limited self-renewal ability, several lines of evidence support their immature state and neurogenic potential and demonstrate expression of biomarkers shared with neural stem cells, including nestin and Rax [43]. The preferential regulation of different tanycyte subpopulations by different stimuli (including cytokine treatment, diets, etc.) correlates with different neuronal differentiation patterns and body weight outcomes, suggesting that perhaps, $\alpha$ tanycytes associate with body weight loss or maintenance, while $\beta$ tanycytes associate with body weight gain [41]. It is important to understand the molecular mechanisms that regulate both chemosensing and the response of tanycytes to various stimuli. Tanycytes possess the molecular machinery that pancreatic beta cells use for their glucosensing. As the STAT3Ser/Hes3 Signaling Axis is now implicated in glucosensing in mouse insulinoma cell lines that are able to release insulin in response to glucose stimulation, and as tanycytes also express Hes3, it will be of great interest to assess whether Hes3 in tanycytes is utilized for their chemosensing properties. It is possible, therefore, that this signaling pathway is used for both cell growth and glucose sensing in both pancreatic beta cells and tanycytes. The median eminence is innervated by neurosecretory cells, positioning $\beta 2$ tanycytes in an ideal location for metabolic sensing. Cerebrospinal fluid insulin and choroid plexus-derived angiopoietin 2 may play a role in the maintenance of Hes3 expression and the immature state of $\beta 2$ tanycytes, as both factors are powerful activators of the STAT3-Ser/Hes3 Signaling Axis [16, 18, 25].

\section{Conclusions}

It is becoming increasingly appreciated that stem/progenitor cell populations in the adult brain play important roles in the function of the nervous system. Immature cells can sense environmental cues and determine whether to quiesce, proliferate, or differentiate, contributing to the plasticity of the tissue they reside in. Elucidating the molecular mechanisms that these cells utilize will help us understand how local and endocrine signals regulate these cells, how to manipulate them, and it will also help explain how they are affected in disease. The STAT3-Ser/ Hes3 Signaling Axis regulates several cell types with stem/progenitor properties not only in the brain and adrenal, but also 
pancreatic islet beta cells that exhibit highly plastic properties and powerful regenerative potential. Several brain areas may be involved in responses to peripheral insulin and the control of behaviors that contribute to obesity [70], including the prefrontal cortex, where Hes3 + cells also reside [71]. Here we focus on the most well studied of these areas, the hypothalamus. We present data that Hes3 is also expressed in tanycytes in the median eminence of the hypothalamus and propose that this pathway may be a new metabolic regulator and that it may be utilized by different brain regions and organs that are part of the endocrine and neuroendocrine systems.

\section{Acknowledgements}

$\nabla$

This work was supported in part by the Helmholtz Alliance ICEMED-Imaging and Curing Environmental Metabolic Diseases, through the Initiative and Network Fund of Helmholtz Association Grant 051_40001, the Deutsche Forschungsgemeinschaft Grant SFB 655, “Cells into tissues," Project A24, and the Deutsche Forschungsgemeinschaft Clinical Research Unit KFO 252.

\section{Conflict of Interest}

The authors declare no conflict of interest.

\section{Affiliations}

${ }^{1}$ Department of Internal Medicine III, Technische Universität Dresden, Dresden, Germany

${ }^{2}$ Department of Craniofacial Development and Stem Cell Biology, King's College London, UK

${ }^{3}$ Lieber Institute for Brain Development, Baltimore, USA

${ }^{4}$ 1st Department of Pediatrics, University of Athens Medical School, Athens, Aghia Sophia Children's Hospital, Athens, Greece

${ }^{5}$ Center for Regenerative Therapies Dresden, Dresden, Germany

${ }^{6}$ Department of Stem Cell Biology, Centre for Biomolecular Sciences, Division of Cancer and Stem Cells, School of Medicine, University of Nottingham, Nottingham, UK

\section{References}

1 Altman J. Are new neurons formed in the brains of adult mammals? Science 1962; 135: 1127-1128

2 Kaplan MS, Hinds JW. Neurogenesis in the adult rat: electron microscopic analysis of light radioautographs. Science 1977; 197: 10921094

3 Kaplan MS. Neurogenesis in the 3-month-old rat visual cortex. J Comp Neurol 1981; 195: 323-338

4 Gould E, Reeves AJ, Graziano MS, Gross CG. Neurogenesis in the neocortex of adult primates. Science 1999; 286: 548-552

5 Eriksson PS, Perfilieva E, Bjork-Eriksson T, Alborn AM, Nordborg C, Peterson DA, Gage FH. Neurogenesis in the adult human hippocampus. Nat Med 1998; 4: 1313-1317

6 Gage FH. Neurogenesis in the adult brain. J Neurosci 2002; 22: 612-613

7 Pera MF, Andrade J, Houssami S, Reubinoff B, Trounson A, Stanley EG, Ward-van Oostwaard D, Mummery C. Regulation of human embryonic stem cell differentiation by BMP-2 and its antagonist noggin. J Cell Sci 2004; 117: 1269-1280

8 Hockfield S, McKay RD. Identification of major cell classes in the developing mammalian nervous system. J Neurosci 1985; 5: 3310-3328

9 Cattaneo E, McKay R. Identifying and manipulating neuronal stem cells. Trends Neurosci 1991; 14: 338-340

10 Sato N, Meijer L, Skaltsounis L, Greengard P, Brivanlou AH. Maintenance of pluripotency in human and mouse embryonic stem cells through activation of Wnt signaling by a pharmacological GSK-3-specific inhibitor. Nat Med 2004; 10: 55-63

11 Dimou L, Gotz M. Glial cells as progenitors and stem cells: new roles in the healthy and diseased brain. Physiol Rev 2014; 94: 709-737
12 Hermann DM, Peruzzotti-Jametti L, Schlechter J, Bernstock JD, Doeppner $T R$, Pluchino $S$. Neural precursor cells in the ischemic brain - integration, cellular crosstalk, and consequences for stroke recovery. Frontiers in cellular neuroscience 2014; 8: 291

13 Sanchez Alvarado A, Yamanaka S. Rethinking differentiation: stem cells, regeneration, and plasticity. Cell 2014; 157: 110-119

14 Craig CG, Tropepe V, Morshead CM, Reynolds BA, Weiss S, van der Kooy D. In vivo growth factor expansion of endogenous subependymal neural precursor cell populations in the adult mouse brain. J Neurosci 1996; 16: 2649-2658

15 Lim DA, Alvarez-Buylla A. Adult neural stem cells stake their ground. Trends Neurosci 2014; 37: 563-571

16 Androutsellis-Theotokis A, Leker RR, Soldner F, Hoeppner DJ, Ravin R, Poser SW, Rueger MA, Bae SK, Kittappa R, McKay RD. Notch signalling regulates stem cell numbers in vitro and in vivo. Nature 2006; 442: 823-826

17 Androutsellis-Theotokis A, Rueger MA, Mkhikian H, Korb E, McKay RD. Signaling pathways controlling neural stem cells slow progressive brain disease. Cold Spring Harb Symp Quant Biol 2008; 73: 403-410

18 Androutsellis-Theotokis A, Rueger MA, Park DM, Mkhikian H, Korb E, Poser SW, Walbridge S, Munasinghe J, Koretsky AP, Lonser RR, McKay $R D$. Targeting neural precursors in the adult brain rescues injured dopamine neurons. Proc Natl Acad Sci U S A 2009; 106: 13570-13575

19 Poser SW, Park DM, Androutsellis-Theotokis A. The STAT3-Ser/Hes3 signaling axis: an emerging regulator of endogenous regeneration and cancer growth. Front Physiol 2013; 4: 273

20 Masjkur J, Levenfus I, Lange S, Arps-Forker C, Poser S, Qin N, Vukicevic $V$, Chavakis T, Eisenhofer G, Bornstein SR, Ehrhart-Bornstein M, Androutsellis-Theotokis $A$. A defined, controlled culture system for primary bovine chromaffin progenitors reveals novel biomarkers and modulators. Stem Cells Transl Med 2014; 3: 801-808

21 Bonni A, Sun Y, Nadal-Vicens M, Bhatt A, Frank DA, Rozovsky I, Stahl $N$, Yancopoulos GD, Greenberg ME. Regulation of gliogenesis in the central nervous system by the JAK-STAT signaling pathway. Science 1997; 278: 477-483

22 Rajan P, McKay RD. Multiple routes to astrocytic differentiation in the CNS. J Neurosci 1998; 18: 3620-3629

23 Levy DE, Darnell JE Jr. Stats: transcriptional control and biological impact. Nat Rev Mol Cell Biol 2002; 3: 651-662

24 Androutsellis-Theotokis A, Chrousos GP, McKay RD, Decherney AH, Kino $T$. Expression profiles of the nuclear receptors and their transcriptional coregulators during differentiation of neural stem cells. Horm Metab Res 2013; 45: 159-168

25 Androutsellis-Theotokis A, Rueger MA, Park DM, Boyd JD, Padmanabhan $R$, Campanati L, Stewart CV, LeFranc Y, Plenz D, Walbridge S, Lonser RR, McKay RD. Angiogenic factors stimulate growth of adult neural stem cells. PLoS One 2010; 5: e9414

26 Androutsellis-Theotokis A, Walbridge S, Park DM, Lonser RR, McKay RD. Cholera toxin regulates a signaling pathway critical for the expansion of neural stem cell cultures from the fetal and adult rodent brains. PLoS One 2010; 5: e10841

27 Lobe CG. Expression of the helix-loop-helix factor, Hes3, during embryo development suggests a role in early midbrain-hindbrain patterning. Mech Dev 1997; 62: 227-237

28 Imayoshi I, Kageyama R. bHLH factors in self-renewal, multipotency, and fate choice of neural progenitor cells. Neuron 2014; 82: 9-23

29 Park DM, Jung J, Masjkur J, Makrogkikas S, Ebermann D, Saha S, Rogliano R, Paolillo N, Pacioni S, McKay RD, Poser S, Androutsellis-Theotokis $A$. Hes3 regulates cell number in cultures from glioblastoma multiforme with stem cell characteristics. Sci Rep 2013; 3: 1095

30 Ohta S, Misawa A, Fukaya R, Inoue S, Kanemura Y, Okano H, Kawakami $Y$, Toda M. Macrophage migration inhibitory factor (MIF) promotes cell survival and proliferation of neural stem/progenitor cells. J Cell Sci 2012; 125: 3210-3220

31 Salewski RP, Buttigieg J, Mitchell RA, van der Kooy D, Nagy A, Fehlings $M G$. The generation of definitive neural stem cells from PiggyBac transposon-induced pluripotent stem cells can be enhanced by induction of the NOTCH signaling pathway. Stem Cells Dev 2012; 22: 383-396

32 Cassady JP, D'Alessio AC, Sarkar S, Dani VS, Fan ZP, Ganz K, Roessler R, Sur $M$, Young $R A$, Jaenisch $R$. Direct lineage conversion of adult mouse liver cells and B lymphocytes to neural stem cells. Stem Cell Rep 2014; 3: $948-956$

33 Ziegler AN, Levison SW, Wood TL. Insulin and IGF receptor signalling in neural-stem-cell homeostasis. Nat Rev Endocrinol 2015; 11: 161-170 
34 Masjkur J, Arps-Forker C, Poser SW, Nikolakopoulou P, Toutouna L, Chenna R, Chavakis T, Chatzigeorgiou A, Chen LS, Dubrovska A, Choudhary P, Uphues I, Mark M, Bornstein SR, Androutsellis-Theotokis A. Hes3 is expressed in the adult pancreatic islet and regulates gene expression, cell growth, and insulin release. J Biol Chem 2014; 289: 35503-35516

35 Poser SW, Chenoweth JG, Colantuoni C, Masjkur J, Chrousos G, Bornstein $S R$, McKay RD, Androutsellis-Theotokis A. Concise review: reprogramming, behind the scenes: noncanonical neural stem cell signaling pathways reveal new, unseen regulators of tissue plasticity with therapeutic implications. Stem Cells Transl Med 2015; 4: 1251-1257

36 Hatakeyama J, Bessho Y, Katoh K, Ookawara S, Fujioka M, Guillemot F, Kageyama $R$. Hes genes regulate size, shape and histogenesis of the nervous system by control of the timing of neural stem cell differentiation. Development 2004; 131: 5539-5550

37 Bachor TP, Suburo AM. Neural stem cells in the diabetic brain. Stem cells international 2012; 820790

38 Masjkur J, Levenfus I, Lange S, Arps-Forker C, Poser S, Qin N, Vukicevic $V$, Chavakis T, Eisenhofer G, Bornstein SR, Ehrhart-Bornstein M, Androutsellis-Theotokis A. A defined, controlled culture system for primary bovine chromaffin progenitors reveals novel biomarkers and modulators. Stem Cells Transl Med 2014; 3: 801-808

39 Hirata H, Ohtsuka T, Bessho Y, Kageyama R. Generation of structurally and functionally distinct factors from the basic helix-loop-helix gene Hes3 by alternative first exons. J Biol Chem 2000; 275: 19083-19089

40 Laufer E, Kesper D, Vortkamp A, King P. Sonic hedgehog signaling during adrenal development. Mol Cell Endocrinol 2012; 351: 19-27

41 Bolborea $M$, Dale $N$. Hypothalamic tanycytes: potential roles in the control of feeding and energy balance. Trends Neurosci 2013; 36: 91-100

42 Xu Y, Tamamaki N, Noda T, Kimura K, Itokazu Y, Matsumoto N, Dezawa $M$, Ide $C$. Neurogenesis in the ependymal layer of the adult rat 3rd ventricle. Exp Neurol 2005; 192: 251-264

43 Lee DA, Bedont JL, Pak T, Wang H, Song J, Miranda-Angulo A, Takiar V, Charubhumi V, Balordi F, Takebayashi H, Aja S, Ford E, Fishell G, Blackshaw S. Tanycytes of the hypothalamic median eminence form a diet-responsive neurogenic niche. Nat Neurosci 2012; 15: 700-702

44 Li J, Tang Y, Cai D. IKKbeta/NF-kappaB disrupts adult hypothalamic neural stem cells to mediate a neurodegenerative mechanism of dietary obesity and pre-diabetes. Nat Cell Biol 2012; 14: 999-1012

45 Altman J, Bayer SA. Development of the diencephalon in the rat. I. Autoradiographic study of the time of origin and settling patterns of neurons of the hypothalamus. The J Comp Neurol 1978; 182: 945-971

46 Altman J, Bayer SA. The development of the rat hypothalamus. Adv Anatom Embryol Cell Biol 1986; 100: 1-178

47 Puelles $L$. Brain segmentation and forebrain development in amniotes. Brain Res Bull 2001; 55: 695-710

48 Maggi R, Zasso J, Conti L. Neurodevelopmental origin and adult neurogenesis of the neuroendocrine hypothalamus. Front Cell Neurosci 2014; 8: 440

49 Zeltser LM, Seeley RJ, Tschop MH. Synaptic plasticity in neuronal circuits regulating energy balance. Nat Neurosci 2012; 15: 1336-1342

50 Gage FH. Mammalian neural stem cells. Science 2000; 287: 1433-1438

51 Suh $H$, Consiglio A, Ray J, Sawai T, D’Amour KA, Gage FH. In vivo fate analysis reveals the multipotent and self-renewal capacities of Sox $2+$ neural stem cells in the adult hippocampus. Cell Stem Cell 2007; 1: $515-528$

52 Rodriguez EM, Blazquez JL, Pastor FE, Pelaez B, Pena P, Peruzzo B, Amat $P$. Hypothalamic tanycytes: a key component of brain-endocrine interaction. Int Rev Cytol 2005; 247: 89-164

53 Mathew TC. Regional analysis of the ependyma of the third ventricle of rat by light and electron microscopy. Anatom Histol Embryol 2008; 37: $9-18$
54 Bradshaw RA. Rita Levi-Montalcini (1909-2012). Nature 2013; 493: 306-306

55 Morton GJ, Cummings DE, Baskin DG, Barsh GS, Schwartz MW. Central nervous system control of food intake and body weight. Nature 2006; 443: 289-295

56 Vigh B, Vigh-Teichmann I, Manzano e Silva MJ, van den Pol AN. Cerebrospinal fluid-contacting neurons of the central canal and terminal ventricle in various vertebrates. Cell Tissue Res 1983; 231: 615-621

57 Barrett P, Ivanova E, Graham ES, Ross AW, Wilson D, Ple H, Mercer JG, Ebling FJ, Schuhler S, Dupre SM, Loudon A, Morgan PJ. Photoperiodic regulation of cellular retinol binding protein, CRBP1 [corrected] and nestin in tanycytes of the third ventricle ependymal layer of the Siberian hamster. J Endocrinol 2006; 191: 687-698

58 Baroncini $M$, Allet C, Leroy D, Beauvillain JC, Francke JP, Prevot V. Morphological evidence for direct interaction between gonadotrophin-releasing hormone neurones and astroglial cells in the human hypothalamus. J Neuroendocrinol 2007; 19: 691-702

59 Wei LC, Shi M, Chen LW, Cao R, Zhang P, Chan YS. Nestin-containing cells express glial fibrillary acidic protein in the proliferative regions of central nervous system of postnatal developing and adult mice. Brain Res Develop Brain Res 2002; 139: 9-17

60 Sidibe A, Mullier A, Chen P, Baroncini M, Boutin JA, Delagrange P, Prevot $V$, Jockers $R$. Expression of the orphan GPR50 protein in rodent and human dorsomedial hypothalamus, tanycytes and median eminence. J Pineal Res 2010; 48: 263-269

61 Bolborea M, Laran-Chich MP, Rasri K, Hildebrandt H, Govitrapong P, Simonneaux V, Pevet P, Steinlechner S, Klosen P. Melatonin controls photoperiodic changes in tanycyte vimentin and neural cell adhesion molecule expression in the Djungarian hamster (Phodopus sungorus). Endocrinology 2011; 152: 3871-3883

62 Chauvet $N$, Prieto M, Alonso G. Tanycytes present in the adult rat mediobasal hypothalamus support the regeneration of monoaminergic axons. Exp Neurol 1998; 151: 1-13

63 Saaltink DJ, Havik B, Verissimo CS, Lucassen PJ, Vreugdenhil E. Doublecortin and doublecortin-like are expressed in overlapping and nonoverlapping neuronal cell population: implications for neurogenesis. J Comp Neurol 2012; 520: 2805-2823

64 Kokoeva MV, Yin H, Flier JS. Neurogenesis in the hypothalamus of adult mice: potential role in energy balance. Science 2005; 310: 679-683

65 Moraes JC, Coope A, Morari J, Cintra DE, Roman EA, Pauli JR, Romanatto $T$, Carvalheira JB, Oliveira AL, Saad MJ, Velloso LA. High-fat diet induces apoptosis of hypothalamic neurons. PLoS One 2009; 4: e5045

66 Purkayastha S, Cai D. Disruption of neurogenesis by hypothalamic inflammation in obesity or aging. Rev Endocr Metab Disord 2013; 14: 351-356

67 Cai D, Liu T. Hypothalamic inflammation: a double-edged sword to nutritional diseases. Ann N Y Acad Sci 2011; 1243: E1-E39

68 Haan N, Goodman T, Najdi-Samiei A, Stratford CM, Rice R, El Agha E, Bellusci S, Hajihosseini MK. Fgf10-expressing tanycytes add new neurons to the appetite/energy-balance regulating centers of the postnatal and adult hypothalamus. J Neurosci 2013; 33: 6170-6180

69 Robins SC, Stewart I, McNay DE, Taylor V, Giachino C, Goetz M, Ninkovic J, Briancon N, Maratos-Flier E, Flier JS, Kokoeva MV, Placzek M. alphaTanycytes of the adult hypothalamic third ventricle include distinct populations of FGF-responsive neural progenitors. Nat Commun 2013; 4: 2049

70 Boersma GJ, Salton SR, Spritzer PM, Steele CT, Carbone DL. Models and mechanisms of metabolic regulation: genes, stress, and the HPA and HPG axes. Horm Metab Res 2012; 44: 598-606

71 Kullmann S, Heni M, Veit R, Scheffler K, Machann J, Haring HU, Fritsche $A$, Preissl $H$. Selective insulin resistance in homeostatic and cognitive control brain areas in overweight and obese adults. Diabetes Care 2015; 38: 1044-1050 